\title{
Adenosine Triphosphate and Adenosine Increase the Pulmonary Blood Flow to Postnatal Levels in Fetal Lambs
}

\author{
G. GANESH KONDURI, ANDREAS A. THEODOROU, ARINDAM MUKHOPADHYAY, \\ AND DEVENDRA R. DESHMUKH \\ Departments of Pediatrics, Children's Hospital of Michigan, Hutzel Hospital and \\ Wayne State University School of Medicine, Detroit, Michigan 48201
}

\begin{abstract}
We investigated the hypothesis that purine nucleotides may mediate the pulmonary vasodilation that occurs at birth in fetal lambs. We studied nine fetal lambs 3 d after placement of intravascular catheters, a flow transducer around the left pulmonary artery, and an inflatable vascular occluder around the ductus arteriosus. The pressure-flow relationship of left lung during a brief occlusion of the ductus arteriosus was studied as an index of pulmonary vascular resistance. We investigated the pulmonary vascular effects of adenosine, ATP, or saline (control) in doses of $0.01-2.50 \mu \mathrm{mol} / \mathrm{kg} / \mathrm{min}$ infused into the right atrial line, and measured blood adenosine and ATP levels in samples from the pulmonary artery and left atrium. We also investigated the mechanism of pulmonary vascular effects of adenosine and ATP. Adenosine and ATP caused significant decreases in pulmonary vascular resistance and increases in pulmonary blood flow in doses of 0.08-2.5 $\mu \mathrm{mol} / \mathrm{kg} / \mathrm{min}$. The pulmonary blood flow increased to levels seen in postnatal lambs at doses of 1.2 and $2.5 \mu \mathrm{mol} / \mathrm{kg} / \mathrm{min}$ of adenosine and ATP. The baseline blood adenosine and ATP levels in fetus were 8 and $70 \%$ of levels in postnatal lambs. ATP concentrations increased to postnatal levels and adenosine levels increased to $\mathbf{2 0 \%}$ of postnatal levels at infusion rates of 1.2 and $2.5 \mu \mathrm{mol} /$ $\mathrm{kg} / \mathrm{min}$. The pulmonary vasodilation caused by adenosine and ATP was attenuated by 8-phenyltheophylline and cibacron blue, respectively, but not by indomethacin. We conclude that adenosine and ATP are pulmonary vasodilators and increase the fetal pulmonary flow to postnatal levels in doses that increase their blood concentrations to $\leq$ postnatal levels. The effects of adenosine and ATP are mediated by stimulation of $P_{1}$ and $P_{2}$ purinergic receptors and are independent of prostacyclin synthesis. Purine nucleotides may be important mediators of pulmonary vasodilation that occurs in the perinatal lamb. (Pediatr Res 31: 451-457, 1992)
\end{abstract}

\section{Abbreviations}

PVR, pulmonary vascular resistance 8-PT, 8-phenyltheophylline ANOVA, analysis of variance $\mathrm{PaO}_{2}$, arterial $\mathrm{O}_{2}$ pressure $\mathrm{PaCO}_{2}$, arterial $\mathrm{CO}_{2}$ pressure

Received August 9, 1991; accepted December 30, 1991.

Correspondence and reprint requests: G. Ganesh Konduri, M.D., Department of Pediatrics, Hutzel Hospital, 4707 St. Antoine Blvd., Detroit, MI 48201.

Supported by a Grant from American Heart Association of Michigan.

1 Presented in part at the Society for Pediatric Research meeting, New Orleans, LA, May 1991.
The fetal lung undergoes significant changes at birth to prepare itself for the function of gas exchange during postnatal life. These changes include a rapid decrease in PVR and a 10-fold increase in pulmonary blood flow (1). The factors that decrease the PVR at birth include onset of ventilation (2) and exposure to higher oxygen tension $(3,4)$. Studies done in fetal lambs have shown that both factors have independent effects $(2,3)$ on fetal pulmonary vessels, although they appear to act in concert at birth. The pulmonary vasodilation caused by ventilation of fetal lamb's lungs can be blocked by indomethacin $(5,6)$ and is accompanied by increased release of prostacyclin into pulmonary circulation (7). However, the increase in pulmonary flow in response to an increase in oxygen tension in the fetal lamb appears to be independent of prostaglandin synthesis $(5,8)$.

We previously reported $(9,10)$ that adenosine and ATP are pulmonary vasodilators in postnatal lambs and that they dilate the pulmonary vessels during hypoxia-induced pulmonary hypertension in lambs. We proposed the hypothesis that increased release of adenosine and ATP in response to an increase in oxygen tension at birth may cause pulmonary vasodilation at birth. The objectives of this study were to determine 1) the response of fetal pulmonary circulation to infusion of exogenous adenosine and ATP, 2) blood levels of these nucleotides in the fetal pulmonary circulation in the baseline state and at each infusion rate of nucleotide, and 3) the mechanism of pulmonary vascular effects of ATP and adenosine in fetal lambs.

\section{MATERIALS AND METHODS}

Nine fetal lambs were studied at $125 \pm 3 \mathrm{~d}$ of gestation (term gestation $=145 \mathrm{~d})$. The fetal lambs were of normal weight $(3.0$ $\pm 0.4 \mathrm{~kg})$ and had normal blood $\mathrm{pH}(7.37 \pm 0.04)$ and $\mathrm{PO}_{2}(18$ $\pm 3 \mathrm{~mm} \mathrm{Hg}$ or $2.5 \pm 0.5 \mathrm{kPa}$ ) at the time of study. All nine fetal lambs were studied to investigate the pulmonary vascular effects of adenosine and ATP and to determine the changes in blood ATP and adenosine levels during the study. Control studies were done with infusion of normal saline and the three experiments were done on separate days. In addition, four fetal lambs were studied with infusion of adenosine after the administration of 8$\mathrm{PT}$, a $\mathrm{P}_{1}$ receptor antagonist. The five other fetal lambs were studied with infusion of ATP after the administration of 8-PT, cibacron blue, a $\mathrm{P}_{2}$ receptor antagonist, or indomethacin. Thus, four fetal lambs were studied four times on separate days and five were studied six times on separate days. The order of the studies was randomized for each of the nine lambs and lambs were allowed to recover for $24 \mathrm{~h}$ between studies. The study was approved by the Animal Investigations' Committee of Wayne State University (Detroit, MI).

Surgical preparation. The ewe underwent a sterile surgical procedure under general anesthesia with isoflurane and oxygen administered via an endotracheal tube. A midline laparotomy 
incision was made and fetal parts were identified by palpation. A uterine incision was made in close proximity to the fetal head, parallel to the uterine vessels. The fetal head was exposed and catheters were inserted into the ascending aorta and right atrium via the carotid artery and jugular vein. Then, a left lateral thoracotomy was done on the fetus and catheters were inserted by direct puncture into the left pulmonary artery and left atrium. An inflatable vascular occluder was placed around the ductus arteriosus (size 10; In Vivo Metric, Healdsburg, CA) with a loose fit, such that the ductus was not compressed when the occluder was deflated. An ultrasonic flow transducer (size $6 \mathrm{~S}$; Transonic Systems Inc., Ithaca, NY) was implanted around the left pulmonary artery to measure the blood flow to the left lung. The thoracotomy and neck incisions were closed and the fetus was returned to the uterine cavity. A large bore catheter was placed in the amniotic cavity to replace amniotic fluid with lactated Ringer's solution and to measure the amniotic cavity pressure, which served as zero reference for fetal intravascular pressures. The catheters and cables for the flow transducer and vascular occluder were exteriorized to the flank of the ewe. The uterine and abdominal incisions were closed, and the ewe was returned to the cage for recovery. Antibiotics (procaine penicillin, 2 million $\mathrm{U}$, and gentamicin, $250 \mathrm{mg}$, intramuscular) were administered to the ewe on the day of surgery and on each postoperative day.

Study protocol. Each animal was allowed to recover for at least $3 \mathrm{~d}$ before experiments were done. For a study, the ewe was placed in a cage in the study area and was allowed free access to alfalfa pellets and water. The fetal intravascular catheters and amniotic fluid catheter were connected to strain gauge manometers (P23 XL, Spectramed Electronics Inc., Critical Care Division, Oxnard, CA) and the flow transducer was connected to an ultrasonic transit time blood flow meter (Transonic Systems Inc.). Aortic, pulmonary arterial, left atrial, and right atrial pressures, and pulmonary blood flow, were recorded on a Grass model 7D polygraph (Grass Instruments, Quincy, MA).

We studied the pressure-flow relationship of left lung during a brief occlusion of ductus arteriosus as an index of fetal PVR, as in the technique described by Abman and Accurso (11). Constriction of the ductus arteriosus in the fetal lamb results in an increase in pulmonary blood flow and release of occlusion causes a return of blood flow to the baseline level. The change in pulmonary artery pressure during the occlusion of ductus was plotted on the $y$ axis and the left pulmonary flow was plotted on the $x$ axis, and the slope (regression coefficient) for the linear portion of the curve was calculated. The slope was calculated for both the increase in flow during the occlusion of the ductus, and for the decrease in flow to baseline, after release of occlusion. We chose to study the pressure-flow relationship of left lung as an index of PVR because the presence of a large ductal shunt renders the traditional method of dividing pulmonary artery pressure by the flow less accurate (12) in the fetus. This technique gave reproducible measurements of PVR in the study animals, and the measurements did not change significantly in control experiments (saline infusion) when the ductus was transiently occluded every $10 \mathrm{~min}$ for $90 \mathrm{~min}$.

Drug preparation. Adenosine and disodium salt of ATP were obtained from Sigma Chemical Co. (St. Louis, MO) in a powder form and the solution for i.v. administration was prepared each day by mixing it with sterile $0.9 \%$ saline to give a final concentration of $4 \mu \mathrm{mol} / \mathrm{mL}$. 8-PT was obtained from Sigma in a powder form and the total dose of $7 \mathrm{mg} / \mathrm{kg}$ was dissolved in 3 $\mathrm{mL}$ of ethyl alcohol. Cibacron blue (Sigma) and indomethacin (Merck Sharp \& Dohme, West Point, PA) were dissolved in normal saline to provide the total dose in $3 \mathrm{~mL}$ of solution.

Protocol for infusion of nucleotides. Baseline hemodynamic variables were recorded and blood samples were drawn from pulmonary artery and left atrium to estimate the blood nucleotide levels in the baseline state. Then, adenosine or ATP was given as a continuous infusion into the right atrial line in a dose of $0.01 \mu \mathrm{mol} / \mathrm{kg} / \mathrm{min}$ with a Harvard infusion pump (Harvard Apparatus, South Natick, MA), and variables were measured after the animals received the infusion for $10 \mathrm{~min}$. The infusion rate was doubled every $10 \mathrm{~min}$ to give the animal $0.02,0.04$, $0.08,0.15,0.30,0.60,1.20$, and $2.50 \mu \mathrm{mol} / \mathrm{kg} / \mathrm{min}$ of ATP or adenosine, and variables were measured at the end of each $10-$ min period. These doses were previously shown to cause pulmonary vasodilation in hypoxic newborn lambs $(9,10)$. Infusion into the right atrial line will ensure that the infused nucleotide is diluted into the right ventricular output. The right ventricular output in fetal lambs is reported to be about $200 \mathrm{~mL} / \mathrm{kg} \mathrm{(12),}$ which is approximately the cardiac output in postnatal lambs (10). The resulting concentrations of the nucleotide in the blood going to the left lung should be comparable to the measured increases in concentrations achieved in the experiments in postnatal lambs. The half-lives for ATP and adenosine appear to be less than $10 \mathrm{~s}$ (13), although data are not available for fetal lambs. Each infusion rate was kept for $10 \mathrm{~min}$ to achieve steady state levels of the blood flow in plasma, assuming that the half-life in fetal lambs does not exceed 1-2 min. Our data in postnatal lambs during hypoxia $(9,10)$ indicate that hemodynamic variables return to baseline state within $1 \mathrm{~min}$ after discontinuation of infusion. We did not observe tachyphylaxis to the pulmonary vascular effects of nucleotides when they were infused over 90 min in fetal lambs. The control experiments were done on a different day with an infusion of an equal volume of saline. The pressure-flow relationship of left lung was studied in the baseline state and at each infusion rate of adenosine or ATP. Blood samples $(0.5 \mathrm{~mL})$ were obtained from pulmonary artery and left atrium at each infusion rate to determine the blood ATP or adenosine levels. The volume of blood taken was $1 \mathrm{~mL}$ at each time point and $10 \mathrm{~mL}$ each for studies with adenosine and ATP. The total volume was $7 \%$ of fetal blood volume (assumed to be $85 \mathrm{~mL} / \mathrm{kg}$ and the average weight of study lambs was $3.0 \mathrm{~kg}$ )

Table 1. Arterial blood gas values and pH data for adenosine, ATP, and control experiments*

\begin{tabular}{|c|c|c|c|c|c|c|c|}
\hline \multirow[b]{2}{*}{ Variable } & \multirow[b]{2}{*}{ Drug } & \multirow[b]{2}{*}{ Baseline } & \multicolumn{5}{|c|}{ Infusion rates of adenosine, ATP, or saline $(\mu \mathrm{mol} / \mathrm{kg} / \mathrm{min})$} \\
\hline & & & 0.04 & 0.15 & 0.60 & 1.20 & 2.50 \\
\hline \multirow[t]{3}{*}{$\mathrm{pHa}$} & Saline & $7.38 \pm 0.03$ & $7.37 \pm 0.02$ & $7.38 \pm 0.03$ & $7.37 \pm 0.04$ & $7.36 \pm 0.03$ & $7.37 \pm 0.04$ \\
\hline & Adenosine & $7.37 \pm 0.02$ & $7.37 \pm 0.03$ & $7.36 \pm 0.04$ & $7.31 \pm 0.04$ & $7.29 \pm 0.04 \uparrow$ & $7.28 \pm 0.05 \uparrow$ \\
\hline & ATP & $7.37 \pm 0.03$ & $7.36 \pm 0.03$ & $7.34 \pm 0.04$ & $7.30 \pm 0.03$ & $7.28 \pm 0.04 \dagger$ & $7.24 \pm 0.05 \dagger$ \\
\hline \multirow[t]{3}{*}{$\mathrm{PaCO}_{2}(\mathrm{~mm} \mathrm{Hg}) \ddagger$} & Saline & $42 \pm 4$ & $40 \pm 3$ & $41 \pm 3$ & $42 \pm 4$ & $39 \pm 3$ & $40 \pm 3$ \\
\hline & Adenosine & $41 \pm 3$ & $41 \pm 4$ & $40 \pm 3$ & $44 \pm 3$ & $48 \pm 3 \dagger$ & $49 \pm 3 t$ \\
\hline & ATP & $39 \pm 4$ & $40 \pm 3$ & $44 \pm 3$ & $46 \pm 3$ & $48 \pm 3 \dagger$ & $49 \pm 4 \dagger$ \\
\hline \multirow[t]{3}{*}{$\mathrm{PaO}_{2}(\mathrm{~mm} \mathrm{Hg}) \ddagger$} & Saline & $18 \pm 3$ & $18 \pm 4$ & $17 \pm 3$ & $18 \pm 2$ & $16 \pm 3$ & $17 \pm 3$ \\
\hline & Adenosine & $17 \pm 3$ & $17 \pm 2$ & $16 \pm 3$ & $15 \pm 2$ & $14 \pm 3$ & $13 \pm 2 \dagger$ \\
\hline & ATP & $17 \pm 3$ & $16 \pm 4$ & $15 \pm 3$ & $14 \pm 3$ & $13 \pm 3$ & $13 \pm 2 \dagger$ \\
\hline
\end{tabular}

* Data are presented as mean $\pm \mathrm{SD}$ for $n=9$. Values are corrected to the animal's body temperature. $\mathrm{pHa}$, arterial $\mathrm{pH}$.

$\dagger p<0.05$ from baseline.

$\ddagger$ Conversion factor for SI units: $1 \mathrm{~mm} \mathrm{Hg}=0.133 \mathrm{kPa}$. 
0 BASELINE $\quad \nabla 0.04 \mu \mathrm{MOL} \quad \triangle 0.15 \mu \mathrm{MOL} \quad \square 2.50 \mu \mathrm{MOL}$
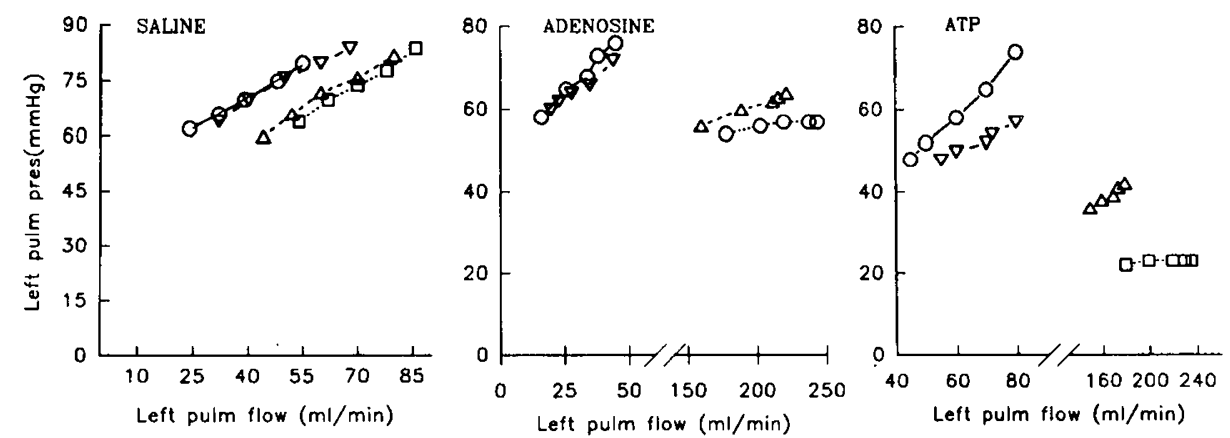

Fig. 1. The pressure-flow relationship of left lung during brief occlusions of the ductus arteriosus is shown here for one animal. The plots are shown during baseline state, and infusions of $0.04,0.15$, and $2.50 \mu \mathrm{mol} / \mathrm{kg} / \mathrm{min}$ doses of saline, adenosine, and ATP. The preocclusion pulmonary flow increased during infusion of adenosine and ATP, which accounts for the differences in the $x$ axis scale for the three experiments.
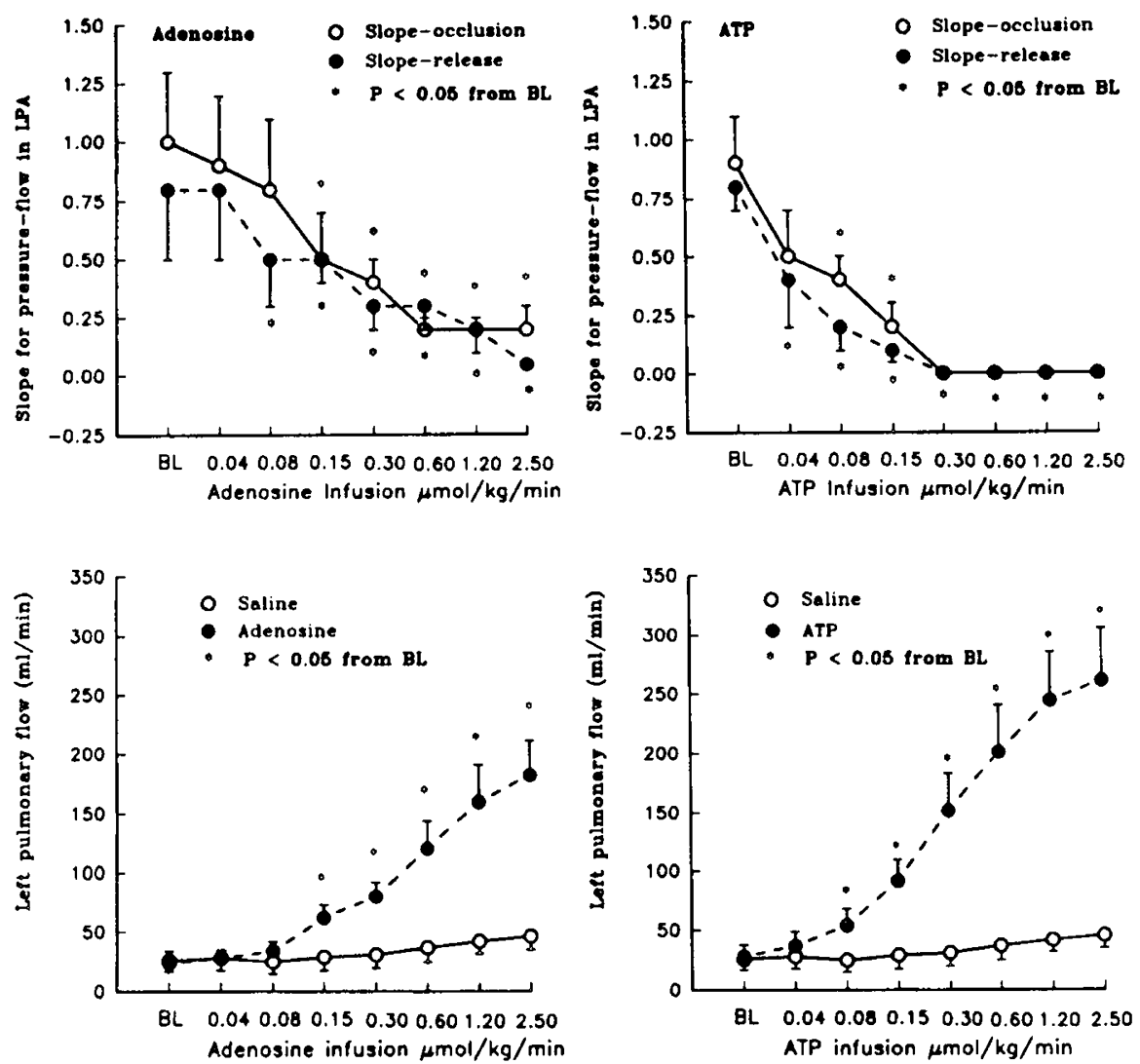

Fig. 2. Pulmonary vascular effects of purine nucleotides in fetal lambs. Slope of the pressure-flow relationship in the left pulmonary artery $(L P A)$ was calculated at each time point during a brief occlusion of the ductus arteriosus, which increases the LPA flow, and after the release of occlusion, when LPA flow returns to baseline. Data are mean $\pm \mathrm{SD}$ for $n=9 .{ }^{*}, p<0.05$ from baseline $(B L)$. Values for left pulmonary flow measured at each time point before the occlusion of the ductus are shown at the bottom. Occlusion of ductus was done for $15 \mathrm{~s}$ and flow returned to the preocclusion level between measurements.

taken over a 2-d period and did not alter the baseline hemodynamic variables significantly.

Studies on postnatal lambs. Blood samples were also obtained from the pulmonary artery and left atrium of nine postnatal lambs at $7 \mathrm{~d}$ of age during normoxia and toward the end of a 10-min exposure to alveolar hypoxia (fraction of inspired oxygen 0.10 ). The concentrations of adenosine and ATP in the samples were measured and were compared to the baseline nucleotide levels in the fetal pulmonary artery and left atrium. The blood samples were collected on the animals before a study of the effects of ATP on newborn lambs during hypoxia, and the results of the study were reported previously (10). These data are shown in Table 2 for the purpose of comparison with adenosine and ATP levels in fetal pulmonary circulation.
Assay for ATP. Blood samples for ATP levels were collected into heparinized syringes and were placed immediately into tubes with trichloroacetic acid kept at $0-4^{\circ} \mathrm{C}$. The samples were immediately centrifuged and supernatant was separated and kept frozen at $-20^{\circ} \mathrm{C}$. Blood ATP levels were measured by an enzymatic assay using phosphoglycerate-phosphokinase and glyceraldehyde phosphate dehydrogenase (Sigma), as in the technique described previously $(10,14)$. The intraassay coefficient of variation was $3-4 \%$ and the interassay coefficient of variation was $3-5 \%$. The minimum detectable concentration of ATP using this assay was $0.1 \mu \mathrm{mol} / \mathrm{dL}$. Assays for all the samples were run in triplicate against a four-point standard curve. The concentration of ATP in blood was expressed as $\mu \mathrm{mol} / \mathrm{dL}$.

Assay for adenosine. Assay for adenosine was done by HPLC 

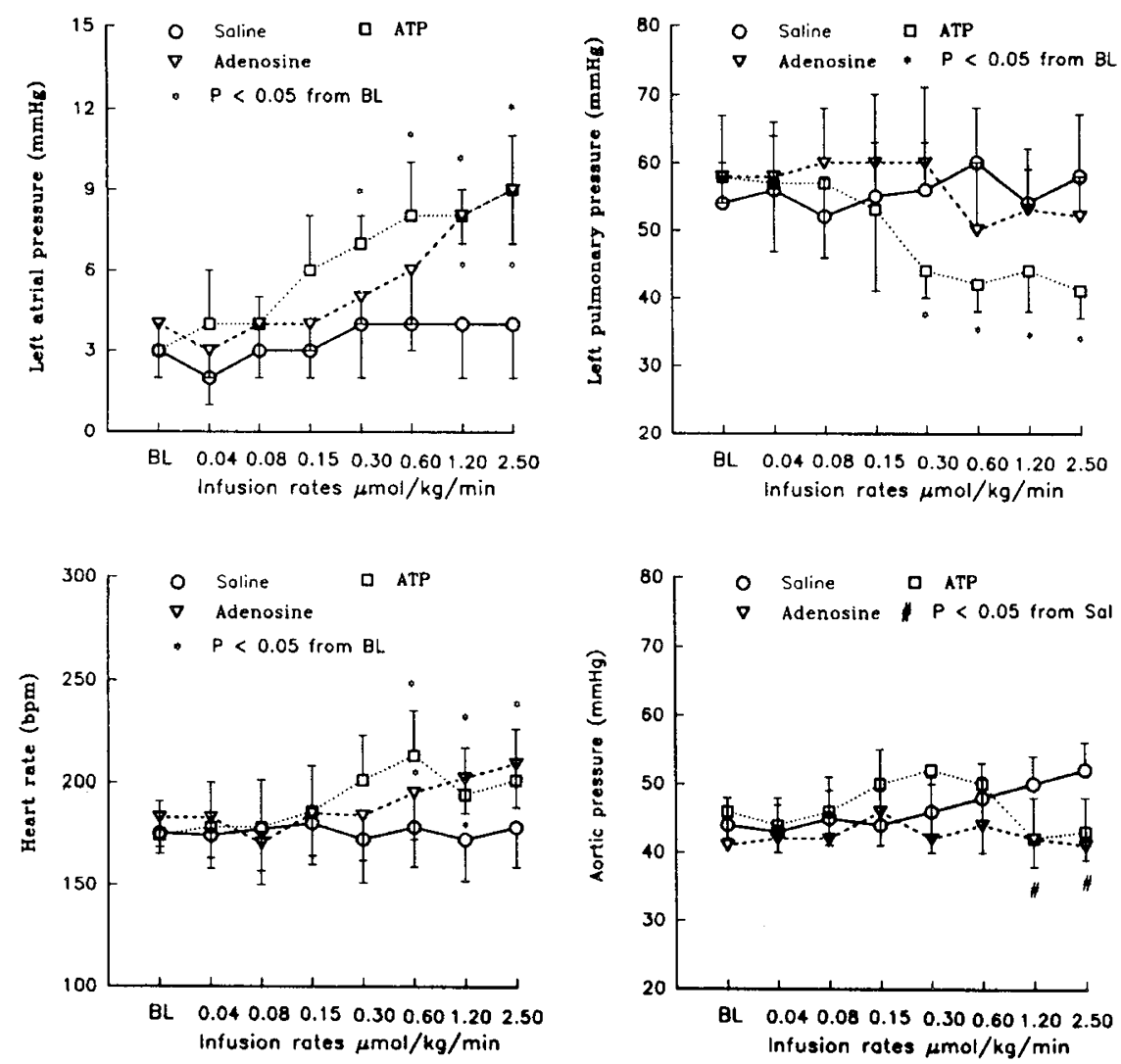

Fig. 3. Effects of saline, adenosine, and ATP on left atrial, left pulmonary arterial, and aortic pressures and heart rate. Data are mean \pm SD for $n=9 .{ }^{*}, p<0.05$ from baseline $(B L)$; \#, $p<0.05$ from control (saline) data obtained at the same time point.

Table 2. Blood adenosine and ATP levels in baseline state in fetal and postnatal lambs and during infusion of adenosine or ATP in fetal lambs*

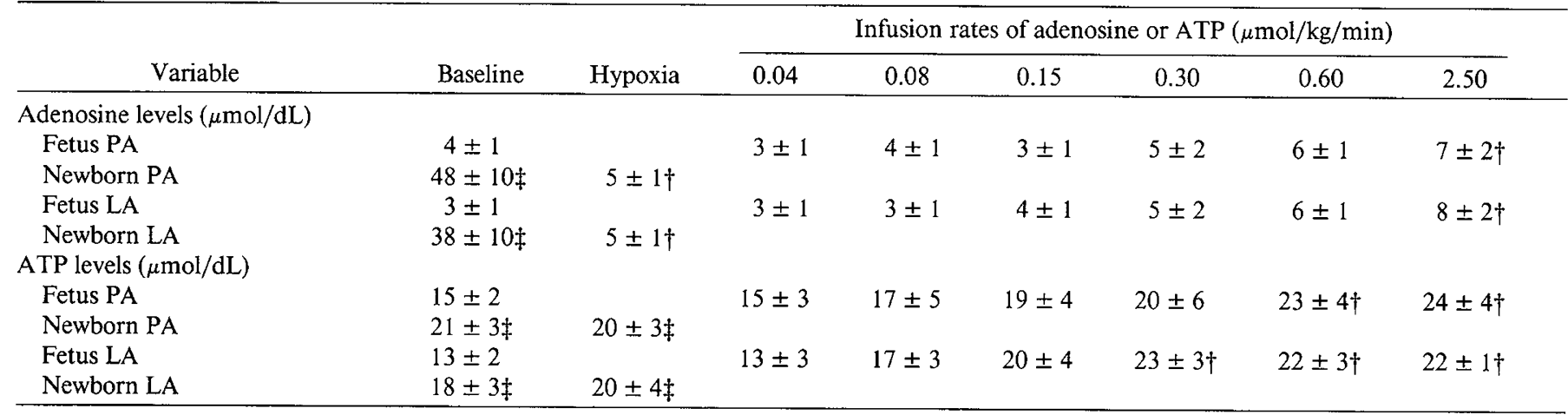

* Data are means \pm SD for $n=9$ for ATP levels, $n=5$ for adenosine levels in fetus, and $n=8$ for adenosine levels in newborn lambs. Hypoxia data were only obtained in newborn lambs during exposure to a fraction of inspired oxygen of 0.10 , resulting in a mean PaO $\mathrm{P}_{2}$ of 36 . PA, pulmonary artery; LA, left atrium.

$\dagger$ Indicates $p<0.05$ from baseline.

$\ddagger$ Indicates $p<0.05$ from baseline data in fetal lambs.

as described by Von Borstel et al. (15). Blood samples were treated as described above for ATP. Adenosine in supernatant was assayed by HPLC (Waters 820 system equipped with an auto sampler and maxima software), using a Waters micro-Bondapak C-18 reversed phase column (Milford, MA). An isocratic method was used to elute adenosine (10\% methanol in $10 \mathrm{mM}$ potassium phosphate, $\mathrm{pH} 5.8$ ) at a flow rate of $1.6 \mathrm{~mL} / \mathrm{min}$. Adenosine was detected by UV absorbance at $254 \mathrm{~nm}$ (Waters $481 \mathrm{UV}$ detector). The blood concentration of adenosine was expressed as $\mu \mathrm{mol} /$ dL. The intraassay and interassay coefficient of variation was $0.3 \%$, and the smallest detectable amount of adenosine was 1 $\mathrm{nmol} / \mathrm{dL}$.

Experiments to investigate mechanism of effects of adenosine and ATP. We investigated the hypothesis that adenosine causes its pulmonary vascular effects predominantly by stimulation of $P_{1}$ purinergic receptors, as previously described in other vascular beds (16). We investigated three possible mechanisms for ATP: 1) ATP undergoes conversion to adenosine (17) and the vasodilator effects are then mediated by adenosine via stimulation of $P_{1}$ purinergic receptors; 2 ) ATP causes vasodilation by stimulation of $\mathrm{P}_{2}$ purinergic receptors (16); and 3) ATP stimulates release of prostacyclin by the endothelial cells, as previously shown (18) in porcine pulmonary artery endothelial cells, and prostacyclin causes pulmonary vasodilation in fetal lambs (19). To confirm our hypothesis for adenosine, four fetal lambs were given $7 \mathrm{mg} /$ $\mathrm{kg}$ of 8-PT into the pulmonary artery as a bolus and hemody- 

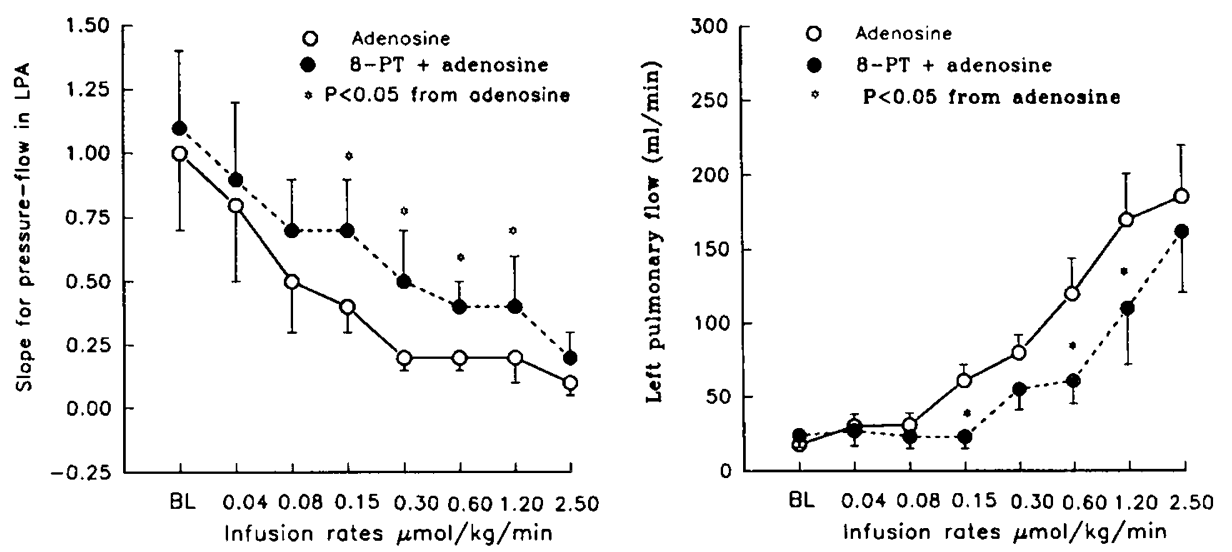

Fig. 4. Effect of 8-PT on pulmonary vasodilation caused by adenosine. Data are mean \pm SD for $n=4$. Baseline data were obtained and adenosine infusion was started $20 \mathrm{~min}$ after a bolus dose of 8-PT. Control for the experiment consists of data obtained with adenosine infusion without prior administration of 8-PT in the same animals on a different day. ${ }^{*}$, significant differences between 8-PT + adenosine and adenosine infusion alone. Slopes for the pressure-flow relationship of left lung are shown during a brief ductal occlusion. Left pulmonary flow data were obtained just before ductal occlusion at each time point.
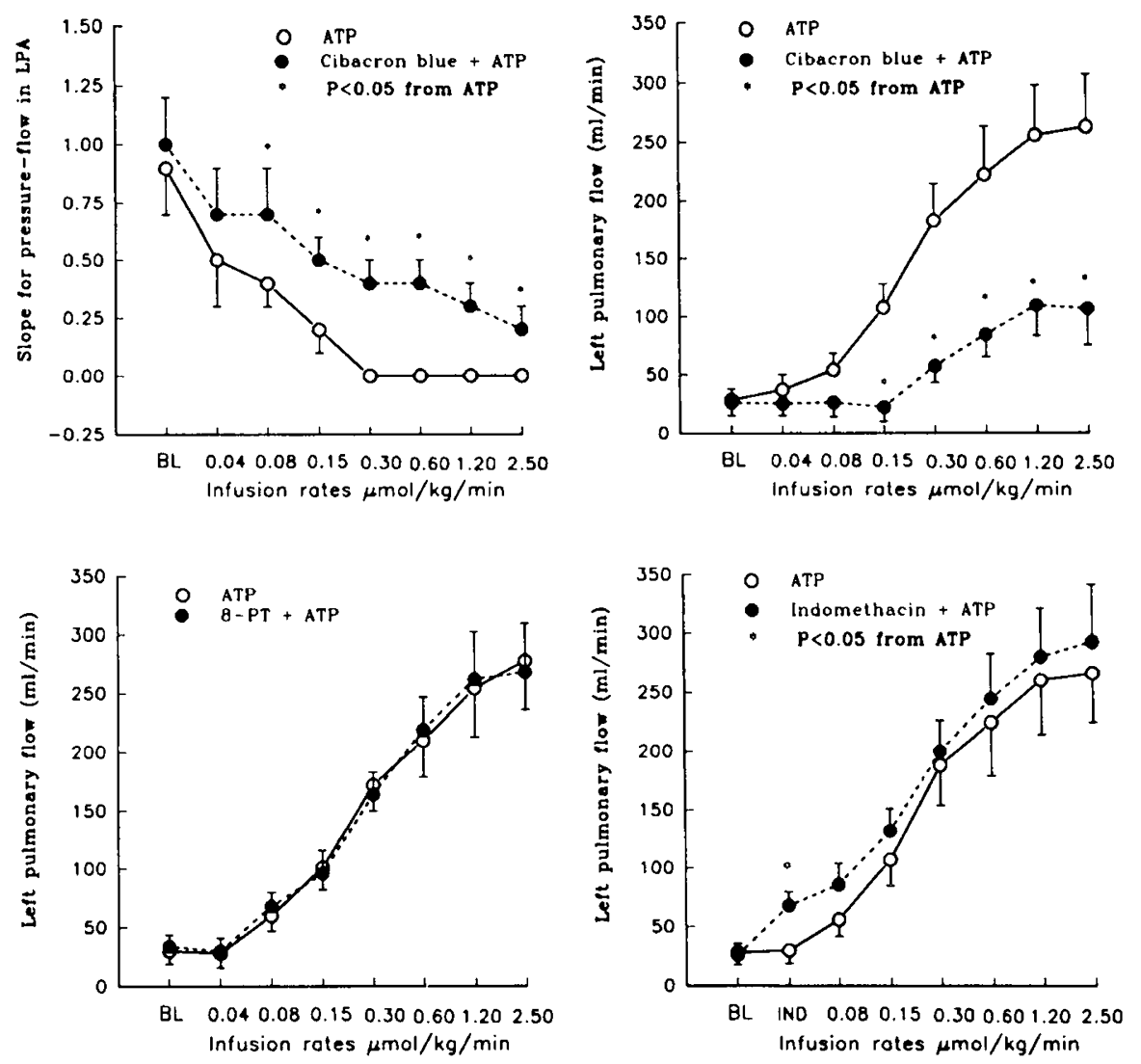

Fig. 5. Data obtained to investigate the mechanism of pulmonary vasodilation caused by ATP in fetal lambs. Data are mean \pm SD for $n=5$. Baseline data $(B L)$ for cibacron blue and 8-PT were obtained 20 min after the administration of these agents. Slope for the pressure-flow relationship of the left pulmonary artery $(L P A)$ was calculated during a brief occlusion of the ductus arteriosus and values shown for left pulmonary flow were obtained before constriction of the ductus at each time point. IND, data obtained 20 min after the administration of indomethacin. *, significant differences $(p<0.05)$ between data obtained with ATP infusion alone and cibacron blue + ATP or indomethacin + ATP.

namic variables were measured after $20 \mathrm{~min}$. Then, an infusion of adenosine was given into the right atrial line in doses of $0.01-$ $2.5 \mu \mathrm{mol} / \mathrm{kg} / \mathrm{min}$ and hemodynamic variables and pressure-flow plots were obtained at each infusion rate, as described above. These data were compared to the data obtained with adenosine infusion alone on the same animals. We investigated the mechanisms for ATP in five other fetal lambs on separate days with administration of $7 \mathrm{mg} / \mathrm{kg} 8$-PT, $5 \mathrm{mg} / \mathrm{kg}$ cibacron blue, or 1 $\mathrm{mg} / \mathrm{kg}$ indomethacin. Hemodynamic variables were measured $20 \mathrm{~min}$ after the administration of one of these drugs and ATP was infused into the right atrial line at doses of $0.01-2.5 \mu \mathrm{mol} /$ $\mathrm{kg} / \mathrm{min}$ as described above. The data obtained with each of the three experiments with ATP are compared to data obtained with ATP infusion alone in the same animals. We allowed the animals to recover for $24 \mathrm{~h}$ between studies with the $P_{1}$ and $P_{2}$ receptor blockers and randomized the order in which the studies were performed. The duration of the blockade caused by these drugs has not been investigated in fetal lambs before, but the baseline hemodynamic variables were comparable before each study.

Statistical analysis. All data are expressed as means \pm 1 SD. 
The baseline data obtained on different days for each experiment were compared by single-factor ANOVA for repeated measures to determine if baseline variables were similar on each day. The data obtained with control, adenosine, and ATP experiments were compared by a two-way ANOVA for repeated measures (20). The data obtained with 8-PT + adenosine, cibacron blue + ATP, 8-PT + ATP, and indomethacin + ATP were compared to data from infusion of adenosine or ATP alone in the same animals by two-way ANOVA for repeated measures. When significant differences, defined as $p<0.05$, were found, a Newman-Keuls multiple range test was done to determine which means were different. The blood ATP and adenosine levels in the pulmonary arterial and left atrial samples were compared with levels obtained in a group of nine postnatal lambs during normoxia and alveolar hypoxia by one-way ANOVA and Newman-Keuls multiple range test.

\section{RESULTS}

Baseline variables measured on different days were comparable and showed no significant differences. The arterial blood gases and blood $\mathrm{pH}$ were within normal range for fetal lambs at this gestation (Table 1). There were no significant changes in these variables during control experiments. The blood $\mathrm{pH}$ decreased and $\mathrm{PaCO}_{2}$ increased significantly at doses of 1.2 and $2.5 \mu \mathrm{mol} /$ $\mathrm{kg} / \mathrm{min}$, and $\mathrm{PaO}_{2}$ decreased at $2.5 \mu \mathrm{mol} / \mathrm{kg} / \mathrm{min}$ of adenosine and ATP.

The pressure-flow plots for the left lung during constriction of the ductus arteriosus are steep in the baseline state, indicating high PVR (Fig. 1). Infusion of saline in the control experiments did not change the slope significantly. Infusion of adenosine or ATP caused a significant and dose-dependent decrease in the slope of pressure-flow plots, both during occlusion of ductus and after release of occlusion (Fig. 2). The slope was zero during infusion of adenosine at 2.5 and ATP at 0.3 to $2.5 \mu \mathrm{mol} / \mathrm{kg} /$ min, when increases in flow during ductal occlusion were not accompanied by increases in pressure. These data indicate a 10fold decrease in PVR in fetal lambs during infusion of adenosine and ATP. The left pulmonary flow was low in the baseline state and showed a small but significant increase when saline was given at the highest infusion rate (Fig. 2). Left pulmonary flow increased significantly and in a dose-dependent manner during infusion of adenosine and ATP at doses of $0.08-2.5 \mu \mathrm{mol} / \mathrm{kg} /$ min. Adenosine and ATP increased the pulmonary blood flow 8- to 10-fold from baseline to levels seen in postnatal lambs at infusion rates of 1.2 and $2.5 \mu \mathrm{mol} / \mathrm{kg} / \mathrm{min}$. The increase in blood flow during ATP infusion was $50 \%$ greater than adenosine infusion at same doses, and the difference is significant by ANOVA.

The left atrial pressure did not change in the control experiments, and increased significantly during infusion of adenosine at 1.2 and $2.5 \mu \mathrm{mol} / \mathrm{kg} / \mathrm{min}$ and ATP at doses of $0.3-2.5 \mu \mathrm{mol} /$ $\mathrm{kg} / \mathrm{min}$ (Fig. 3). The pulmonary artery pressure did not change significantly during control experiments or during infusion of adenosine (Fig. 3). ATP caused a significant decrease in pulmonary artery pressure at doses of $0.3-2.5 \mu \mathrm{mol} / \mathrm{kg} / \mathrm{min}$, sufficient to lower it below the systemic pressure. The heart rate increased when adenosine and ATP were given at doses $\geq 0.60 \mu \mathrm{mol} / \mathrm{kg} /$ min and did not change in control experiments (Fig. 3). The decreases in aortic pressure (Fig. 3) at 1.2 and $2.5 \mu \mathrm{mol} / \mathrm{kg} / \mathrm{min}$ infusion rates of adenosine and ATP were not significant compared with baseline data for those experiments, but were lower than control data obtained with saline.

Baseline blood adenosine levels in fetal lambs were 10 -fold lower than baseline levels in postnatal lambs, and are comparable to adenosine levels measured in postnatal lambs during hypoxia (Table 2). Increases in pulmonary flow during adenosine infusion were accompanied by small increases in blood adenosine levels in pulmonary artery and left atrium. The baseline blood ATP levels in fetal lambs were significantly lower than in postnatal lambs (Table 2) and increased to postnatal levels during ATP infusion at doses of $0.60-2.50 \mu \mathrm{mol} / \mathrm{kg} / \mathrm{min}$. Clearance of ATP by the pulmonary circulation appeared to be rapid when ATP was infused in doses $\leq 0.30 \mu \mathrm{mol} / \mathrm{kg} / \mathrm{min}$. Infusion of larger doses of ATP resulted in significant increases in blood ATP levels in pulmonary artery and left atrium. Adenosine appeared to be cleared rapidly when infused in doses $\leq 0.6 \mu \mathrm{mol} / \mathrm{kg} / \mathrm{min}$, with a significant rise in blood levels when infused in larger doses.

8-PT did not alter the baseline hemodynamic variables significantly. The increase in pulmonary flow and decrease in slope of pressure-flow plots of left lung during adenosine infusion were attenuated by pretreatment of animals with 8-PT (Fig. 4). The decreases in slope of pressure-flow plots and increases in pulmonary flow during ATP infusion were attenuated by cibacron blue (Fig. 5). Cibacron blue and 8-PT did not alter the baseline hemodynamic variables significantly. The baseline pulmonary flow and pulmonary artery pressure were increased significantly by indomethacin. Indomethacin and 8-PT did not alter the increase in pulmonary blood flow caused by ATP (Fig. 5).

\section{DISCUSSION}

We provide the evidence that the purine nucleotides, adenosine and ATP, are pulmonary vasodilators in fetal lambs and that their baseline blood levels are lower than in postnatal lambs. We also present the evidence that the vasodilator effects of adenosine and ATP are mediated predominantly by stimulation of $P_{1}$ and $P_{2}$ purinergic receptors, respectively. These data indicate that purine nucleotides may be important mediators of perinatal changes in pulmonary circulation.

The factors that lower the PVR at birth include onset of ventilation and an increase in oxygen tension. The relative contribution of the two factors, i.e. mechanical expansion of the lung versus increase in oxygen tension, to the decrease in PVR is not clear. Ventilation of the lungs in fetal lambs with nitrogen causes a 4-fold decrease in PVR, and ventilation with air, which increases the oxygen tension, causes the 10-fold decrease in PVR seen at birth (5). Inhibition of prostaglandin synthesis prevents the decrease in PVR in response to distension of lung without oxygenation, but not the 10 -fold decrease in PVR that occurs when ventilation is accompanied by oxygenation (5).

Oxygen is a major stimulus that decreases the PVR at birth. Morin et al. (4) have shown that an increase in fetal oxygen tension to postnatal levels, without distension of lungs, increases the pulmonary blood flow to levels seen in newborn lambs. However, the mechanism by which oxygen increases the pulmonary blood flow is not known. Indomethacin does not appear to prevent the oxygen-induced decrease in PVR (8). Our studies indicate that adenosine and ATP are pulmonary vasodilators capable of increasing the pulmonary blood flow to postnatal levels in fetal sheep. The pulmonary vasodilation caused by ATP is independent of prostaglandin synthesis, as previously shown for oxygen (8). An increase in ATP concentrations in the pulmonary artery of fetal lambs to levels seen in postnatal lambs resulted in pulmonary vasodilation of the magnitude seen at birth. The blood adenosine levels in pulmonary circulation in postnatal lambs (mean $\mathrm{PaO}_{2} 82 \mathrm{~mm} \mathrm{Hg}$ or $10.9 \mathrm{kPa}$ ) decreased 10-fold during alveolar hypoxia (mean $\mathrm{PaO}_{2} 36 \mathrm{~mm} \mathrm{Hg}$ or 4.8 $\mathrm{kPa}$ ) to levels that are slightly higher than those measured in fetal lambs (mean $\mathrm{PaO}_{2}$ of $18 \mathrm{~mm} \mathrm{Hg}$ or $2.5 \mathrm{kPa}$ ). These data indicate that blood adenosine levels in pulmonary circulation change in proportion to oxygen tension. Small increases in blood adenosine levels in the fetus caused significant increases in pulmonary flow. The pulmonary blood flow reached postnatal levels even at concentrations of adenosine that are well below the levels measured in postnatal lambs. These data indicate that the pulmonary vessels in near-term fetal lambs are very sensitive to the vasodilator effects of adenosine.

The purine nucleotides appear to exert their vasodilator effects by stimulation of specific receptors present on endothelial and 
smooth muscle cells of blood vessels. Burnstock (16) proposed that the effects of purine nucleotides are mediated by two types of purinergic receptors. $P_{1}$ receptors are more sensitive to adenosine, act via the adenylate cyclase system, and are inhibited by methylxanthines. $P_{2}$ receptors are more sensitive to ATP, and are not antagonized by methylxanthines. Based on receptor affinity and ligand binding studies, $P_{1}$ receptors have been further classified into $A_{1}$ and $A_{2}$ subtypes: $A_{1}$ receptors inhibit adenylate cyclase and appear predominantly in heart, where they mediate the negative chronotropic and inotropic effects of adenosine; $\mathrm{A}_{2}$ receptors are present on the vascular endothelial cells, stimulate adenylate cyclase, and mediate the vasodilator effects of adenosine. $P_{2}$ receptors are also classified into $P_{2 x}, P_{2 y}, P_{2 z}$, and $P_{2 t}$ receptors. The relative predominance of these receptors on the cell varies between different organs, $P_{2 y}$ receptors being more predominant in the lung. The $P_{2 y}$ receptors are blocked by cibacron blue, and ATP appears to be the more potent agonist for these receptors. In the endothelial cells, the effects of adenosine and ATP appear to be mediated by an increase in the intracellular CAMP levels (21) and probably by a decrease in the calcium influx into the cell (22). Because the endothelial cells are in constant contact with blood, the blood levels of the nucleotides are probably important determinants of their endothelium-mediated vascular effects. Therefore, measurement of blood levels of these nucleotides appears to be important to define the effects of endogenous adenosine and ATP in baseline state on the pulmonary circulation, and the effects of exogenous infusions of nucleotides into the pulmonary circulation. We have shown that the effects of adenosine are attenuated by 8-PT, a $\mathbf{P}_{1}$ receptor antagonist, and the effects of ATP are attenuated by cibacron blue, a $\mathrm{P}_{2}$ receptor antagonist. Although the increase in pulmonary flow during the infusion of adenosine or ATP was not completely blocked by these agents, the dose-response curves for adenosine and ATP were shifted to the right, indicating attenuation of response. The maximal response to the $2.5 \mu \mathrm{mol} /$ $\mathrm{kg} / \mathrm{min}$ infusion rate of adenosine was not affected by $8-\mathrm{PT}$, indicating a competitive antagonism between adenosine and its blocker at the receptor level (23). The dose of indomethacin used $(1 \mathrm{mg} / \mathrm{kg})$ is based on previous studies. Tyler et al. (24) have shown that $1.9 \mathrm{mg} / \mathrm{kg}$ indomethacin accentuates the hypoxic pulmonary vasoconstriction in premature newborn goats at comparable gestation (132 d). A dose of $0.30 \mathrm{mg} / \mathrm{kg}$ has been shown (25) to decrease prostaglandin synthesis in premature newborn infants. We observed a significant increase in pulmonary blood flow with this dose of indomethacin, indicating inhibition of prostaglandin synthesis in ductus arteriosus. However, indomethacin did not cause a shift in the dose-response relationship for ATP, indicating that prostacyclin is probably not responsible for the pulmonary vascular effects of ATP. We provide the evidence for presence of $P_{1}$ and $P_{2}$ purinergic receptors in the pulmonary vessels of fetal lambs. This information will be useful in understanding the role of these nucleotides as pulmonary vasodilators in the perinatal period.

The magnitude of pulmonary vasodilation caused by ATP is $50 \%$ greater than adenosine at comparable doses. Because ATP is rapidly metabolized to adenosine by the ectonucleotidase on vascular endothelial cells (17), this may serve as a mechanism to regulate the extent of vasodilation in response to ATP. The blood levels of adenosine appear to be greater than ATP levels in postnatal lambs, but are 4-fold lower than ATP levels in fetal lambs. The significance of these differences is not clear from our studies.

The heart rate increased and blood $\mathrm{pH}$ decreased when adenosine and ATP were given in doses that increased the pulmonary flow 10 -fold above baseline. The reason for these changes may be a decrease in the systemic flow across the ductus arteriosus secondary to a significant increase in pulmonary flow. ATP caused a larger increase in pulmonary flow than adenosine and a greater decrease in blood $\mathrm{pH}$ at $2.5 \mu \mathrm{mol} / \mathrm{kg} / \mathrm{min}$ infusion rate. The $\mathrm{PaCO}_{2}$ increased and $\mathrm{PaO}_{2}$ decreased at these doses of nucleotides, indicating a decrease in placental blood flow. These data are consistent with a decrease in systemic flow during infusion of nucleotides at $0.6-2.5 \mu \mathrm{mol} / \mathrm{kg} / \mathrm{min}$ doses.

In summary, our studies indicate that adenosine and ATP have significant pulmonary vasodilator effects in fetal lambs. Their blood levels in the pulmonary circulation increase significantly from fetal to postnatal life in lambs. They increase the fetal pulmonary flow to postnatal levels at blood concentrations $\leq$ blood levels seen in postnatal pulmonary circulation. Their vasodilator effects are mediated by stimulation of $P_{1}$ and $P_{2}$ purinergic receptors present in the pulmonary circulation of fetal lambs. Their role as mediators of oxygen-induced pulmonary vasodilation at birth should be investigated further in fetal lambs.

\section{REFERENCES}

1. Dawes GS, Mott JC, Widdicombe JG, Wyatt DG 1953 Changes in the lungs of the newborn lamb. J Physiol (Lond) 121:141-162

2. Cassin S, Dawes GS, Mott JC, Ross BB, Strang LB 1964 The vascular resistance of the foetal and newly ventilated lung of the lamb. J Physiol (Lond) 171: $61-79$

3. Accurso FJ, Alpert B, Wilkening RB, Petersen RG, Meschia G 1986 Timedependent response of fetal pulmonary blood flow to an increase in fetal oxygen tension. Respir Physiol 63:43-52

4. Morin FC, Egan EA, Ferguson W, Lundgren CEG 1988 Development of pulmonary vascular response to oxygen. Am J Physiol 254:H542-H546

5. Velvis H, Moore P, Heyman MA 1991 Prostaglandin inhibition prevents the fall in pulmonary vascular resistance as a result of rhythmic distension of the lungs in fetal lambs. Pediatr Res 30:62-68

6. Tod ML, Yoshimura K, Rubin LJ 1991 Indomethacin prevents ventilationinduced decreases in pulmonary vascular resistance of the middle region in fetal lambs. Pediatr Res 29:449-454

7. Leffler CW, Hessler JR, Green RS 1984 The onset of breathing at birth stimulates pulmonary vascular prostacyclin synthesis. Pediatr Res 18: 938-942

8. Morin FC, Egan EA, Norfleet WT 1988 Indomethacin does not diminish the pulmonary vascular response of the fetus to increased oxygen tension. Pediatr Res 24:696-700

9. Konduri GG, Woodard LL 1990 Adenosine is a pulmonary vasodilator in newborn lambs. Pediatr Res 27:61A(abstr)

10. Konduri GG, Woodard LL 1991 Selective pulmonary vasodilation by low dose infusion of adenosine triphosphate in newborn lambs. J Pediatr 119: 94-102

11. Abman SH, Accurso FJ 1989 Acute effects of partial compression of ductus arteriosus on fetal pulmonary circulation. Am J Physiol 257(Heart Circ Physiol 26):H626-H634

12. Dawes GS 1968 Foetal and Neonatal Physiology. Year Book Medical Publishers Inc, Chicago, pp 79-90

13. Klabunde RE 1983 Dipyridamole inhibition of adenosine metabolism in human blood. Eur J Pharmacol 93:21-26

14. Adams H 1963 Adenosine 5 '-triphosphate determination with phosphoglycerate kinase. In: Bergmeyer HU (ed) Methods of Enzymatic Analysis. Academic Press, New York, pp 539-543

15. Von Borstel RW, Wurtman RJ, Conlay LA 1983 Chronic caffeine consumption potentiates the hypotensive action of circulating adenosine. Life Sci 32: $1151-1158$

16. Burnstock G 1990 Overview: purinergic mechanisms. In: Dubyak GR, Fedan JS (eds) Biological Actions of Extracellular ATP. Ann NY Acad Sci, New York, pp $1-18$

17. Dieterle Y, Ody C, Ehrensberger A, Stalder H, Junod AF 1978 Metabolism and uptake of adenosine triphosphate and adenosine by porcine aortic and pulmonary endothelial cells and fibroblasts in culture. Circ Res 42:869-876

18. Pearson JD, Slakey LL, Gordon JL 1983 Stimulation of prostaglandin production through purinoceptors on cultured porcine endothelial cells. Biochem J 214:273-276

19. Leffler CW, Hessler JR 1979 Pulmonary and systemic vascular effects of exogenous prostaglandin $I_{2}$ in fetal lambs. Eur $J$ Pharmacol 54:37-42

20. Winer BJ 1971 Statistical principles in experimental design. McGraw-Hill Book Co, New York, pp 514-603

21. Silver PJ, Walus K, Disalvo J 1984 Adenosine mediated relaxation and activation of cyclic AMP-dependent protein kinase in coronary arterial smooth muscle. J Pharmacol Exp Ther 228:342-347

22. Su C 1985 Extracellular functions of nucleotides in heart and blood vessels. Annu Rev Physiol 47:665-676

23. Ross EM, Gilman AG 1985 Pharmacodynamics: Mechanisms of drug action and the relationship between drug concentration and effect. In: Gilman AG, Goodman LS, Rall TW, Murad F (eds) The Pharmacological Basis of Goodman LS, Rall TW, Murad F (eds) The Pharmacological
Therapeutics. MacMillan Publishing Co, New York, pp 35-48

24. Tyler T, Wallis R, Leffler C, Cassin S 1975 The effects of indomethacin on the pulmonary vascular response to hypoxia in the premature and mature newborn goat. Proc Soc Exp Biol Med 150:695-698

25. Seyberth HW, Rascher W, Hackenthal R, Wille L 1983 Effect of prolonged indomethacin therapy on renal function and selected vasoactive hormones in very-low-birth-weight infants with symptomatic patent ductus arteriosus. J Pediatr 103:979-984 